Received 00th January 20xx, Accepted 00th January 20xx

DOI: $10.1039 / x 0 x x 00000 x$

\section{Nanomolar detection of adenosine triphosphate (ATP) using a nanostructured fluorescent chemosensing ensemble ${ }^{\dagger}$}

\author{
Ling-Xi Huang, ${ }^{\ddagger}, \mathrm{a}$ Qing Guo, ${ }^{\ddagger, a}$ Yong Chen, ${ }^{\mathrm{b}}$ Peter Verwilst, ${ }^{\mathrm{c}}$ Subin Son, ${ }^{\mathrm{c}} \mathrm{Jia-Bin} \mathrm{Wu},{ }^{\mathrm{a}}$ Qian-Yong \\ $\mathrm{CaO}^{*, a}$ and Jong Seung $\mathrm{Kim}^{*, c}$
}

We report a novel nanostructured chemosensing ensemble PyNpC13/UD, obtained by self-assembling uranine dye (UD) and an amphiphilic pyridinium salt PyNp-C13. The ensemble was developed for the fluorescence turn-on sensing of ATP in aqueous solutions and inside living cells. The assembly operates via an indicator displacement assay (IDA) method with an ultra-low detection limit of $6.8 \mathrm{nM}$.

The development of novel fluorescent chemosensors to selectively detect bioactive anions in the complex matrix of biosystems has attracted increasing attention, due to the relatively simplicity and high sensitivity of the fluorescence technique. ${ }^{1}$ Among these various anions, sensors for adenosine triphosphate (ATP) have received particular attention, as ATP not only plays a crucial physiological role, ${ }^{2}$ but concentrations outside of the normal 1-10 mM range are also is also observed in several diseases, such as malignant tumours, Alzheimer's disease and Parkinson's disease. ${ }^{3}$

At present, the most widely used approach for designing ATP-sensitive probes is based on the reporter-spacer-receptor (RSR) mechanism, in which the fluorophore signalling unit is covalently attached to an anion receptor. ${ }^{4}$ These covalently linked RSR probes often need time-consuming and complicated organic synthesis. A solution to this problem, under the form of so-called chemosensing ensembles, also known as indicator displacement assays (IDAs), were pioneered by the Inouye and Shinkai groups. ${ }^{5}$ With this indirect approach, the receptor and indicator dyes form a reversible host/dye complex via non-covalent bonds (hydrogen bonds, electrostatic attraction, hydrophilic and hydrophobic interactions, $\pi-\pi$ stacking, van der Waals forces or coordination). Analytes compete with the dye and expel the dye from the host, resulting in changes in the optical properties of the dye. The IDA approach shows some advantages over RSRs, such as the ease of synthesis and a wider availability of indicators to allow for the modulation of detection emission wavelengths.

\footnotetext{
a. Department of Chemistry, Nanchang University, Nanchang 330031, P. R. China Fax: (+86)791-83969386; E-mail: cqyong@ncu.edu.cn

b. Institute for Advanced Study, Nanchang University, Nanchang 330031, China c. Department of Chemistry, Korea University, Seoul 02841, Korea. E-mail:

jongskim@korea.ac.kr

+ Electronic Supplementary Information (ESI) available: Experimental details, NMR spectra and additional spectroscopic data. See DOI: 10.1039/x0xx00000x

¥ These authors contributed equally
}

Until now, various host/dye chemosensing ensembles for the recognition of metal ions, anions and biomolecular species have been described. ${ }^{6}$ Some examples for sensing of ATP and other nucleoside polyphosphates were also reported, ${ }^{7}$ examples commonly employ macrocyclic receptors, such as cyclophanes, calixarenes, cyclodextrins, cucurbiturils and pillararenes as they show a good binding affinity toward various dyes with remarkable changes in their optical properties. $^{8}$ In this work we employ self-aggregated amphiphilic pyridinium salts as the host, further simplifying the design of the IDA.

Recently, self-assembled nanostructured materials have been attracting much attention in the chemosensor field for their superior characteristics, such as high sensitivity and excellent biocompatibility. ${ }^{9}$ While some fluorescent amphiphile-based nanoaggregates for the recognition of ATP and other related triphosphate nucleotides have been developed, the design usually consists of an amphiphilic RSR design. ${ }^{10}$ Here, we report a nanostructured chemosensing ensemble PyNp-C13/UD (see scheme 1) based on the indicator displacement assay (IDA) method.

The amphiphilic pyridinium-based receptor PyNp-C13 was designed based on the following rationale: (1) the multiple pyridinium and amide donors can efficiently participate in anion binding via hydrogen bonding and/or electrostatic interactions, (2) the long dodecylcetyl chain enables self-

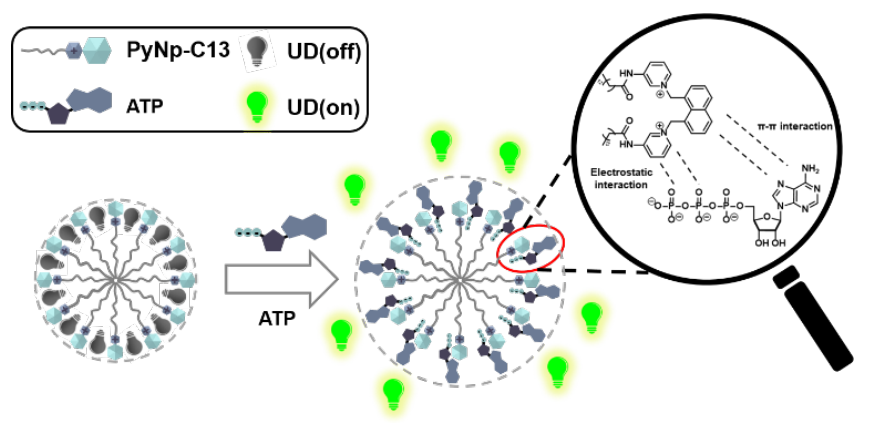

Scheme 1. The structure of PyNp-C13 the IDA-based ATP sensing mechanism. 

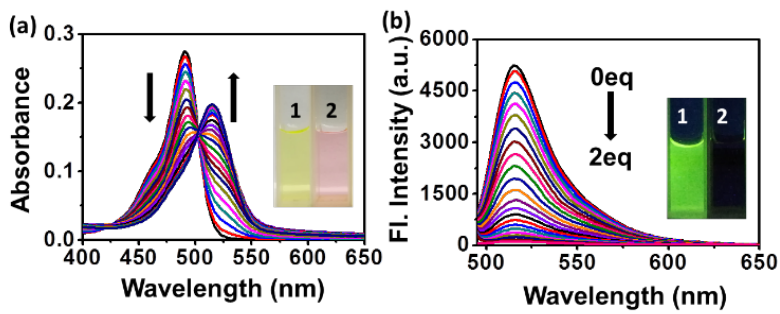

Fig. 1 The UV-vis (a) and fluorescence (b) spectra of UD ( $6 \mu \mathrm{M}, \lambda e x=490 \mathrm{~nm})$ upon addition of various amounts of PyNp-C13 in HEPES (10 mM, pH = 7.4) buffer solution. The inset shows the colour change of UD and after then addition of 2.0 equivalent of PyNp-C13 in ambient light and with excitation at $365 \mathrm{~nm}$ using a hand-held UV light.

assembly in aqueous solutions due to hydrophobic interactions, and (3) pyridinium is a useful fluorescence quenching unit. ${ }^{11}$ Using the commercially available uranine dye (UD) as the fluorescent indicator, we found that PyNp-C13 binds well with the anionic dye and results in a self-assembled nanostructure (PyNp-C13/UD) in pure aqueous solutions. As a result of PET (photoinduced electron transfer) quenching from the pyridinium salt to UD, the fluorescence of the ensemble was very weak, but competition with ATP liberated the fluorescent dye resulting in a large increase in fluorescence.

The synthesis of the amphiphilic receptor PyNp-C13, following a literature procedure, is described in detail in the supplementary information $\left(\mathrm{ESI}^{+}\right)$and the compound, alongside a short-chain analogue (PyNp-C1), was fully characterized by ${ }^{1} \mathrm{H} /{ }^{13} \mathrm{C} \mathrm{NMR}$ and $\mathrm{HR}-\mathrm{MS}$.

We first studied the interactions between UD and PyNpC13, using absorbance and fluorescence spectroscopy. The successive addition of PyNp-C13 to UD $(6 \mu \mathrm{M})$ in a HEPES (1.0 $\mathrm{mM}, \mathrm{pH}=7.4$ ) buffer solution resulted in a gradual decrease in the absorption of UD at $490 \mathrm{~nm}$ concomitant with the formation a new peak at $515 \mathrm{~nm}$ (Figs. $1 \mathrm{a}$ and S1, ESIt), with a characteristic isosbestic point at $502 \mathrm{~nm}$, indication formation only one species host-guest inclusion complex. The addition of PyNp-C13 also resulted in a drastic change in UD fluorescence at $515 \mathrm{~nm}$ (Figs. $1 \mathrm{~b}$ and S2, ESIT), with a nearly complete fluorescence quenching (99.5\%) upon addition of $12 \mu \mathrm{M}$ PyNpC13. The emission quantum yield (QY) and emission lifetime of UD and PyNp-C13/UD were also investigated, with the QYs of $31.7 \%$ and $0.3 \%$, and the lifetime values of $4.5 \mathrm{~ns}$ and $3.2 \mathrm{~ns}$ (Fig. S3, ESIt), respectively. Clearly, PyNp-C13 and UD can form a stable complex in aqueous solutions, which may be attributed to the electrostatic interaction and/or hydrogen bonding between the cationic PyNP-C13 host with the anionic UD. The Benesi-Hildebrand analysis of the emission data gave a 2:1 stoichiometry complexation for the PyNp-C13/UD ensemble, with a binding constant of $3.42 \times 10^{10} \mathrm{M}^{-2}$.

The formation of the PyNp-C13/UD ensemble was further confirmed by a Tyndall experiment, dynamic light scattering (DLS) and transmission electron microscopy (TEM). It was observed that the free receptor PyNp-C13 and UD are soluble at the tested concentration without a Tyndall phenomenon, however the PyNp-C13/UD ensemble exhibits a clear Tyndall effect (Fig. S4, ESI + ). Clearly, the PyNp-C13/UD ensemble selfassembled into micelle-like nano-structured aggregates. A DLS experiment indicated that the PyNp-C13/UD nanoassemble shows an average hydrated diameter of $115 \mathrm{~nm}$ in aqueous solutions, while the TEM data shows sphere-like aggregates (a)

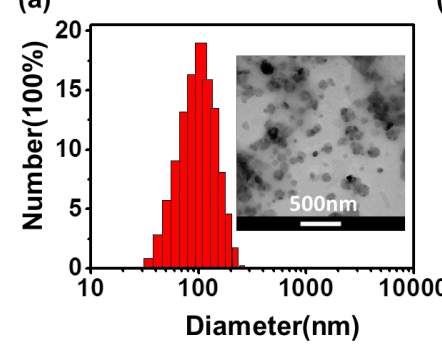

(b)

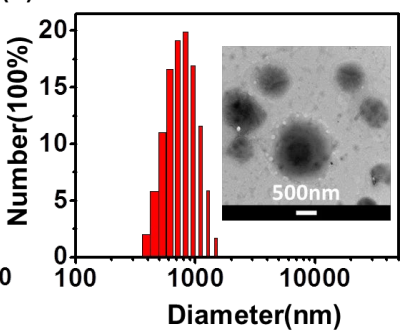

Fig. 2 The size distribution of PyNp-C13/UD assemble before (a) and after (b) addition 8 equivalents of ATP in aqueous solution. The insets show their corresponding TEM images.

with a diameter of 60-90 $\mathrm{nm}$ in the solid state (Fig. 2).

We further tested the potential of a PyNp-C13/UD ensemble $(12 \mu \mathrm{M} / 6 \mu \mathrm{M})$ in a HEPES buffer as an IDA system for polyphosphate anions such as ATP. Upon the addition of ATP, the absorbance of the PyNp-C13/UD ensemble at $515 \mathrm{~nm}$ gradually blue shifted to $490 \mathrm{~nm}$, as the solution colour recovered from pink to yellow (Fig. S5, ESIT). Additionally, a broad absorbance at 530-600 $\mathrm{nm}$ became apparent during the titration as well, which can be attributed to the formation of larger nanoaggregates.

The emission titration results also confirm that the addition of ATP can recover the UD green emission (Fig. 3a). The gradually increasing emission process is saturated with addition of about 8 equivalents ATP, and the fluorescence recovery rate reaches $68.9 \%$. The binding constant between PyNp-C13/UD and ATP was determined to be $1.0 \times 10^{11} \mathrm{M}^{-2}$ according to the emission titration data (Fig. S6, ESI+), with a
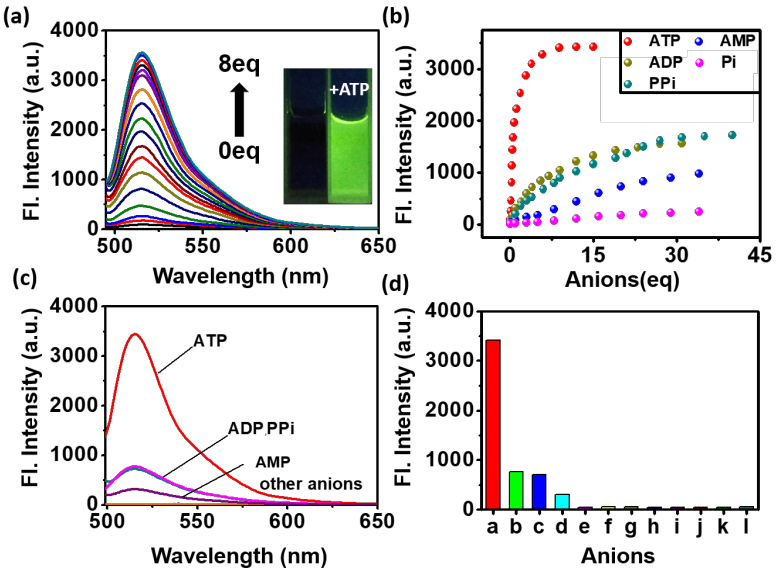

Fig. 3 (a) Fluorescence changes of PyNp-C13/UD $\left(12 \mu \mathrm{M} / 6 \mu \mathrm{M}, \lambda_{\mathrm{ex}}=490 \mathrm{~nm}\right)$ upon addition of various amounts of ATP in a HEPES solution (10 mM, pH = 7.4); inset shows fluorescence of PyNp-C13/UD before and after the addition of 8.0 equivalent of ATP using a hand-held UV light. (b) Fluorescence intensities of PyNp-C13/UD at $515 \mathrm{~nm}$ versus the number of equivalents of several phosphate anions. (c) Fluorescence spectra of PyNp-C13/UD $(12 \mu \mathrm{M} / 6 \mu \mathrm{M})$ before and after the addition of 4.0 equivalent of several phosphate anions in a HEPES buffered solution. (d) Relative fluorescence histogram chart of PyNp-C13/UD at $515 \mathrm{~nm}$ upon addition of 8 equiv. of various anions (a: ATP, b: ADP, c: PPi, d: AMP, e: Pi, f: $\mathrm{AcO}^{-}, \mathrm{g}: \mathrm{F}^{-}, \mathrm{h}: \mathrm{Cl}^{-}, \mathrm{i}: \mathrm{Br}^{-}, \mathrm{j}: \mathrm{I}^{-}, \mathrm{k}: \mathrm{CO}_{3}{ }^{2-}, \mathrm{l}: \mathrm{SO}_{4}{ }^{2-}$ ). 
2:1 stoichiometry. In addition, the detection limit of PyNpC13/UD toward ATP was calculated to be $6.8 \mathrm{nM}$, indicating that this system can efficiently and quantitatively detect ATP at very low concentrations.

Subsequently, we repeated similar experiments in the presence of other phosphate anions, including ADP and AMP, inorganic phosphates $\mathrm{PP}_{\mathrm{i}}$ and $\mathrm{P}_{\mathrm{i}}$, and other biologically relevant anions $\left(\mathrm{ACO}^{-}, \mathrm{F}^{-}, \mathrm{Cl}^{-}, \mathrm{Br}^{-}, \mathrm{I}^{-}, \mathrm{CO}_{3}{ }^{2-}, \mathrm{SO}_{4}{ }^{2-}\right)$. A moderate to weak response toward $\mathrm{PPi}, \mathrm{ADP}$ and $\mathrm{AMP}$, with a partial recovery of the absorption and emission spectra of UD, was observed (Figs. S7-9, ESI+). The binding constants and detection limits of PyNp-C13/UD toward these anions were also calculated and listed in Table S1 (ESI + ). Interesting, the complexation ratio between these anions and PyNp-C13/UD follows a 1:1 stoichiometry. As can be seen the binding affinity of PyNpC13/UD toward these polyphosphates follows the order of ATP $>\mathrm{ADP} \approx \mathrm{PPi}>\mathrm{AMP}$. Thus, the PyNp-C13/UD ensemble is a useful sensor for fluorescence detection of ATP in neutra aqueous solutions. The selectivity for ATP over ADP and AMP is important, because the ATP/ADP ratio in cells is an important modulator for a variety of cellular events. ${ }^{12}$

The high displacement affinity of PyNp-C13/UD toward ATP over ADP, PP and other anions can also be confirmed by DLS experiments (Fig S10, ESI + ). The mean size of the PyNpC13/UD nanoaggregation ensemble shows a large increase from $106 \mathrm{~nm}$ to $1100 \mathrm{~nm}$ after displacement by ATP anions in aqueous solutions. Only a moderate size increase was observed for ADP $(290 \mathrm{~nm})$ and $\mathrm{PP}_{\mathrm{i}}(250 \mathrm{~nm})$, while other ions did not induce significant changes. These results are further confirmed by the TEM data, in which the spherical aggregates of PyNp-C13/UD changed from a diameter of $60-90 \mathrm{~nm}$ to 500-900 $\mathrm{nm}$ upon addition of ATP (Fig. 2).

In addition, we also investigated the sensing ability of the control compound PyNp-C1, which lacks the long hydrophobic alkyl tail. PyNp-C1 shows weaker binding ability toward UD anions compared to PyNp-C13 $\left(3.42 \times 10^{10} \mathrm{M}^{-2}\right.$ vs $8.4 \times 10^{9}$ $\mathrm{M}^{-2}$, Fig. S11, ESI + ), with a lower fluorescence quenching ratio (99.5\% vs $87.2 \%)$. In addition, the formed PyNp-C1/UD assemble exhibits a much lower recognition ability toward ATP (17.8\%, Fig. S12, ESI + ), thus confirming the benefit of the selfassembled nano-sized micelle architecture.

The larger UV-vis absorption and fluorescence changes indicate strong interaction between PyNp-C13 and ATP/UD anions, which is further confirmed by ${ }^{1} \mathrm{H}$ NMR titrations in DMSO-d6/ $\mathrm{D}_{2} \mathrm{O}(8: 2, v / v)$. As shown in Fig. S13 (ESIt), the pyridinium protons $\mathrm{H}_{a}, \mathrm{H}_{b}$ and $\mathrm{H}_{c}$ and methylene protons $\mathrm{H}_{d}$ of PyNp-C13 locate at 9.37, 8.63, 8.36, 6.48 ppm, respectively. Upon addition of ATP or UD anions, these protons display an obviously down-filed shift. Compared with PyNp-C13/UD $(\Delta \delta=$ 0.07, 0.07, 0.13 and $0.09 \mathrm{ppm}$, respectively), PyNp-C13/ATP $(\Delta \delta=0.21,0.14,0.19$ and $0.14 \mathrm{ppm}$, respectively) shows larger changes in chemical shift, which is consistent with stronger interactions for ATP relative to UD.

In order to achieve the sensing ability of ATP in cells, the influence of $\mathrm{pH}$ on the fluorescence response of PyNp-C13/UD was investigated (Fig. 5a). It was found that PyNp-C13/UD showed only a weak response in highly acid solutions $(\mathrm{pH}<5)$ (a)

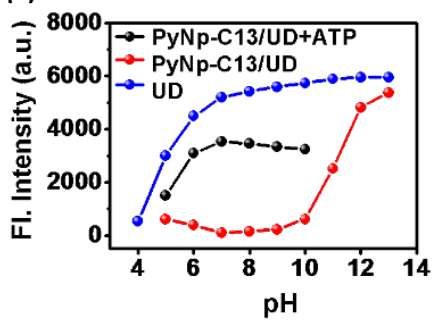

(b)

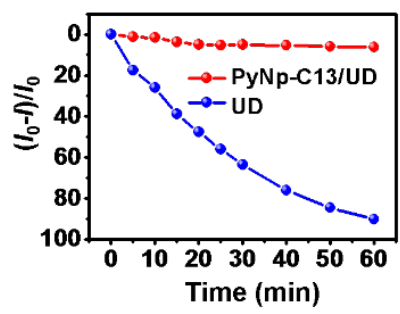

Fig 4. (a) Fluorescence intensity at $515 \mathrm{~nm}$ of UD $(6 \mu \mathrm{M})$, PyNp-C13/UD $(12 \mu \mathrm{M} / 6 \mu \mathrm{M})$ and PyNp-C13/UD + ATP (10 equivalents) at different $\mathrm{pH}$ values. (b) Fluorescence stability of UD $(6 \mu \mathrm{M})$ and PyNp-C13/UD $(12 \mu \mathrm{M} / 6 \mu \mathrm{M})$ with increasing exposure time of xenon lamp (300 W). The fluorescence intensity of PyNp-C13/UD was recorded as fluorescence intensity loss (\%) in the presence of ATP $(60 \mu \mathrm{M})$ at $\mathrm{pH} 7.4$.

as well as under alkaline conditions $(\mathrm{pH}>11)$. However, a remarkable fluorescence enhancement was observed in the $\mathrm{pH}$ range of 6-10, indicating that PyNp-C13/UD can detect ATP under physiological conditions. The influence of other anions on the sensitivity towards ATP was also studied. As shown in Fig. S14 (ESI + ), virtually no interference was observed.

A photo-stability experiment of PyNp-C13/UD (12 $\mu \mathrm{M} / 6$ $\mu \mathrm{M})$ in a HEPES buffered solution was carried out, where the ensemble was first exposed to a $300 \mathrm{~W}$ xenon lamp, then ATP was added and the fluorescence intensity at $515 \mathrm{~nm}$ was recorded. As shown in Fig 5b, PyNp-C13/UD exhibits high photo-stability, with the fluorescence intensity loss $<5 \%$ under continuous irradiation for $1 \mathrm{~h}$. By contrast, a solution of UD alone results in almost $90 \%$ fluorescence bleaching. This difference may be attributed to a shielding effect by PyNpC13, in which can prevent interactions between UD molecules and decrease the probability of photochemical reactions between excited UD and reactive species such as water and oxygen. ${ }^{10 d}$ In addition, UD in the PyNp-C13/UD ensemble is maintained in a dark emission state, further causing resistance to photo-oxidation and photo-bleaching.

Because of the good selectivity and high affinity of PyNpC13/UD toward ATP, we next applied this probe to image the ATP levels in living cells. First, the cytotoxicity of PyNp-C13/UD (2:1 ratio) was tested in murine liver cancer cells (Hepa1-6). With the concentration of the nanostructure ranging from 0 to $40 \mu \mathrm{M}$, more than $80 \%$ cell survival was observed after incubation for 24 hours, demonstrating the low toxicity of this

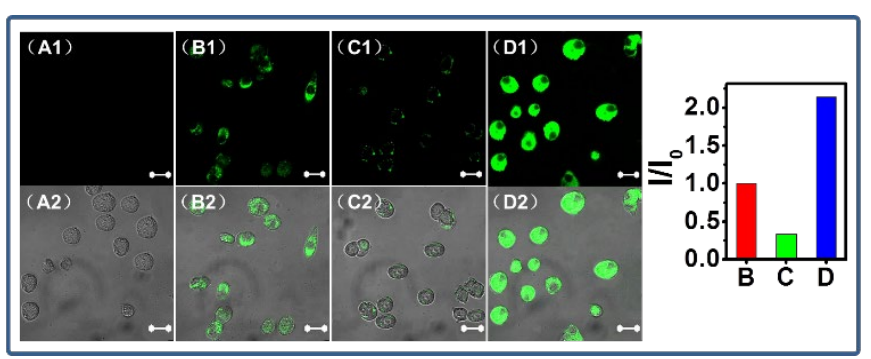

Fig 5. Fluorescent monitoring of the ATP level in living Hepa1-6 cells. Left: CLSM images of Hepa1-6 alone (A1 and A2); PyNp-C13/UD (12 $\mu \mathrm{M} / 6 \mu \mathrm{M})$ was incubated with Hepa16 cells for $2 \mathrm{~h}$ (B1 and B2); Hepa1-6 cells were first treated with $10 \mathrm{mM} \mathrm{NaN}_{3}$ and then incubated with PyNp-C13/UD for 2 hours. (C1 and C2); Hepa1- 6 cells were first treated with $5 \mathrm{mM} \mathrm{Ca}^{2+}$ and then incubated with PyNp-C13/UD for 2 hours. (D1 and D2). Scale bar, $20 \mu \mathrm{m}$. Right: Relative fluorescence intensity of $B, C$, and $D$. 
assemble (Fig. S15, ESIt). Having confirmed the low cytotoxicity of the nanostructured IDA sensor, the ensemble's potential for ATP sensing was tested in living cells. Fig. 6 shows the CLSM images of PyNp-C13/UD (12 $\mu \mathrm{M} / 6 \mu \mathrm{M})$ incubated with living Hepa1-6 cells. To control the cellular ATP levels, three sets of cells were selected: a control sample, cells treated with sodium azide $(5 \mathrm{mM})$, and cells treated with $\mathrm{Ca}^{2+}$ ( $5 \mathrm{mM}$ ). Sodium azide was used as a mitochondrial poison, uncoupling the mitochondrial oxidative phosphorylation (OXPHOS) to inhibit mitochondrial ATPase, and thus induce an abrupt decrease of ATP concentration, ${ }^{13}$ while $\mathrm{Ca}^{2+}$ activates dehydrogenase in mitochondria, thereby raising the concentration of NADH and ATP. ${ }^{14}$ As shown in Fig. 6, the addition of sodium azide resulted in the decrease of fluorescence intensity up to $33.3 \%$, compared to the control group, while treatment of cells with $\mathrm{Ca}^{2+}$ resulted in $214.3 \%$ increase fluorescence. Thus, PyNp-C13/UD demonstrated the capability for monitoring ATP levels in living cells.

To assess the applicability of PyNp-C13/UD toward ATP in more complex environments, the fluorescence imaging experiments were performed in living C. elegans (Fig. S16, ESI $\left.{ }^{\dagger}\right)$. The $C$. elegans were pretreated with exogenous ATP $(100 \mu \mathrm{M})$ at $20^{\circ} \mathrm{C}$ for $4 \mathrm{~h}$, and then incubated with PyNpC13/UD $(40 \mu \mathrm{M} / 20 \mu \mathrm{M})$ for further $3 \mathrm{~h}$. Strong green fluorescence was observed in the entire $C$. elegans body. In contrast, C. elegans treated with only PyNp-C13/UD (Fig.S20 B) exhibited negligible fluorescence. These results indicate the feasibility and reliability of the present assay for ATP detection under practical biological conditions.

In conclusion, we successfully applied a cationic pyridinium amphiphile PyNp-C13 to the recognition of ATP using the IDA method. This receptor can self-assemble with UD to form nonfluorescent PyNp-C13/UD nanoaggregates via multiple electrostatic interactions, hydrogen bonding and hydrophobic interactions in aqueous solutions. This PyNp-C13/UD ensemble demonstrated a highly sensitivity and selectivity toward ATP for the successful displacement of the fluorescent indicator UD from the complex, with a fluorescence turn-on response. In addition, PyNp-C13/UD demonstrates a low cytotoxicity and a high cell permeability and is suitable for imaging ATP levels in living cells. This system shows advantages over previously reported methods, such as easy synthesis, simple operation, high photo-stability and the detection of ATP levels in vitro in pure aqueous solutions. The expansion of the current design toward other nucleoside phosphates and IDAs with different indicators are in currently in progress.

This work was supported by the National Nature Science Foundation of China (No. 21762028, QYC), the Interdisciplinary Innovation Fund of Nanchang University (Project No. 20199166-27060003, QYC), and by a CRI project (No. 2018R1A3B1052702, JSK) of the National Research Foundation of Korea (NRF).

\section{Conflicts of interest}

There are no conflicts to declare.

\section{Notes and references}

1 (a) N. Busschaert, C. Caltagirone, R. W. Van and P. A. Gale, Chem. Rev., 2015, 115, 8038-8155; (b) T. D. Ashton, K. A. Jolliffe and F. M. Pfeffer, Chem. Soc. Rev., 2015, 44, 45474595; (c) P. A. Gale and C. Caltagirone, Coord. Chem. Rev., 2018, 354, 2-27. (d) J. Wu, W. Liu, J. Ge, H. Zhang and P. Wang, Chem. Soc. Rev., 2011, 40, 3483-3495.

2 (a) J. R. Knowles, Ann. Rev. Biochem., 1980, 49, 877-919; (b) A. V. Gourine, E. Llaudet, N. Dale and K. M. Spyer, Nature, 2005, 436, 108-111.

3 G. Burnstock, Trends. Pharmacol. Sci., 2006, 27, 166-176.

4 (a) A. E. Hargrove, S. Nieto, T. Zhang, J. L. Sessler and E. V. Anslyn, Chem. Rev., 2011, 111, 6603-6782; (b) S. Lee, K. K. Yuen, K. A. Jolliffe and J. Yoon, Chem. Soc. Rev., 2015, 44, 1749-1762; (d) Q. Zhao, Z. Zhang and Y. Tang, Chem. Commun., 2017, 53, 9414-9417; (e) L. Wang, L. Yuan, X. Zeng, J. Peng, Y. Ni, J. C. Er, W. Xu, B. K. Agrawalla, D. Su, B. Kim and Y. T. Chang, Angew. Chem. Int. Ed., 2016, 55, 17731776; (g) D. Maity, M. Li, M. Ehlers and C. Schmuck, Chem. Commun., 2017, 53, 208-211; (h) H.-B. Cheng, Z. W. Sun, N. Kwon, R. Wang, Y. Cui, C. O. Park, and J. Yoon, Chem. Eur. J., 2019, 25, 3501-3504; (i) G. Jiang, W. Zhu, Q. Chen, A. Shi, Y. Wu, G. Zhang, X. Li, Y. Li, X. Fan and J. Wang, Analyst, 2017, 142, 4388-4392.

5 (a) B. T. Nguyen and E. V. Anslyn, Coord. Chem. Rev., 2006, 250, 3118-3127; (b) J. Wu, B. Kwon, W. Liu, E. V. Anslyn, P. Wang and J. S. Kim, Chem. Rev., 2015, 115, 7893-7943.

6 (a) Y. Liu, L. Perez, M. Mettry, C. J. Easley, R. J. Hooley and W. Zhong, J. Am. Chem. Soc., 2016, 138, 10746-10749; (b) M. A. Beatty, J. Borges-Gonzalez, N. J. Sinclar, A. T. Pye and F. Hof, J. Am. Chem. Soc., 2018, 140, 3500-3504; (c) A. Norouzy, Z. Azizi and W. M. Nau, Angew. Chem. Int. Ed., 2015, 54, 792795; (d) V. E. Zwicker, B. L. Oliveira, J. H. Yeo, S. T. Fraser, G. J. L. Bernardes, E. J. New and K. A. Jolliffe, Angew. Chem. Int Ed., 2019, 58, 3087-3091.

7 (a) J. Deng, K. Wang, M. Wang and P. Yu, J. Am. Chem. Soc., 2017, 139, 5877-5882; (b) P. P. Neelakandan, M. Hariharan and D. Ramaiah, J. Am. Chem. Soc., 2006, 128, 1133411335; (c) J. Gao, J. Li, W. C. Geng, F. Y. Chen, X. Duan, Z. Zheng, D. Ding and D. S. Guo, J. Am. Chem. Soc., 2018, 140, 4945-4953; (d) M. Bojtár, J. Kozmaa, Z. Szakács, D. Hesszc, M. Kubinyi and I. Bitter, Sens. Actuators B Chem., 2017, 248 305-310.

8 R. Kumar, A. Sharma, H. Singh, P. Suating, H. S. Kim, K. Sunwoo, I. Shim, B. C. Gibb and J. S. Kim, Chem. Rev., 2019, 119, 9657-9721.

9 (a) X. Ma and Y. Zhao, Chem. Rev., 2015, 115, 7794- 7839; (b) R. Klajn, J. F. Stoddart and B. A. Grzybowski, Chem. Soc Rev., 2010, 39, 2203- 2237; (c) G. Yu, K. Jie and F. Huang, Chem. Rev., 2015, 115, 7240-7303; (d) C. T. Li, Y. L. Xu, J. G. Yang, Y. Chen, H. S. Kim, Q. Y. Cao and J. S. Kim, Sens. Actuators B Chem., 2017, 251, 617-623; (e) Q. Guo, Y. Zhang, Z. H. Lin, Q. Y. Cao and Y. Chen, Dyes Pigments, 2020, 172, 107872.

10 (a) H. Tao, L. He, G. Cheng and Q.-Y. Cao, Dyes Pigments, 2019, 166, 233-238; (b) J. H. Zhu, C. Yu, Y. Chen, J. Shin, Q.-Y. Cao and J. S. Kim, Chem. Commun., 2017, 53, 4342-4345; (c) X. Li, X. Guo, L. Cao, Z. Xun, S. Wang, S. Li, Y. Li and G. Yang, Angew. Chem. Int. Ed., 2014, 53, 7809-7813.

11 L. Cheng, H. Zhang, Y. Dong, Y. Zhao, Y. Yu and L. Cao, Chem. Commun., 2019, 55, 2372-2375.

12 S. H. Hewitt, J. Parris, R. Mailhot and S. J. Butler, Chem. Commun., 2017, 53, 12626-12629.

13 M. W. Bowler, M. G. Montgomery, A. G. Leslie and J. E. Walker, Proc. Natl. Acad. Sci. U.S.A., 2006, 103, 8646-8649.

14 E. J. Griffiths and G. A. Rutter, Biochim. Biophys. Acta Bioenerg., 2009, 1787, 1324-1333. 